Çukurova Üniversitesi Mühendislik Mimarlık Fakültesi Dergisi, 29(2), 55-68 ss., Aralık 2014

Çukurova University Journal of the Faculty of Engineering and Architecture, 29(2), pp. 55-68, December 2014

\title{
Bigadiç (Balıkesir) Bentonit Yataklarının Mineralojisi ve Jeokimyası ve Bentonitleşme Sırasındaki Ana, Eser ve Nadir Toprak Elementlerinin Mobilizasyonu
}

\author{
Fazlı ÇOBAN ${ }^{* 1}$ \\ Balıkesir Üniversitesi, Mühendislik-Mimarlık Fakültesi, Jeoloji Mühendisliği Bölümü, Balıkesir
}

Geliş tarihi: 01.09.2014 Kabul tarihi:24.10.2014

\section{Özet}

Bigadiç volkano-sedimanter havzasında erken Miyosen'de etkili olan asidik volkanizma ürünleri (dasit, riyodasit, riyolit lavları ve bunların piroklastikleri) ile ilişkili birçok bentonit yatağı bulunur. İnceleme bölgesinde camsal-kristal tüflerin yerinde alterasyonu ile meydana gelen bentonit yataklarının mineralojikkimyasal özellikleri belirlenerek; bentonitleşme sırasında ana, eser ve nadir toprak elementlerinin (REE) davranışı incelenmiştir. XRD incelemelerine göre bentonit yataklarında ana kil minerali Camontmorillonit'tir. Plajiyoklas, sanidin, biyotit, kalsit, Ca-dolomit, kuvars, kristobalit, opal-CT, illit, kaolinit ve alünit ise yaygın safsızlıkları oluşturur. Bentonitlerin tüm kayaç kimyasal analizleri, ana kayaç ile karşılaştırıldığında bentonitleşme sırasında bentonitlerde $\mathrm{MgO}, \mathrm{CaO}, \mathrm{H}_{2} \mathrm{O}, \mathrm{TiO}_{2}, \mathrm{Fe}_{2} \mathrm{O}_{3}$ ve $\mathrm{Al}_{2} \mathrm{O}_{3}$ kazançları, buna karşılık $\mathrm{Na}_{2} \mathrm{O}, \mathrm{K}_{2} \mathrm{O}$ ve $\mathrm{SiO}_{2}$ kayıpları olmuştur. Benzer olarak bentonitleşme sırasında Rb, Cs, U, Y kayıpları ve Zn, Sr, Zr kazançları belirlenmiştir. Diğer taraftan; bentonitleşme ile Ağır Nadir Toprak Elementleri (HREE) izafi olarak fakirleşirken Hafif Nadir Toprak Elementleri (LREE) bentonitte zenginleşmiştir.

Anahtar Kelimeler: Bigadiç (Balıkesir), Bentonitleşme, Element mobilizasyonu.

\section{The Mineralogy and Geochemistry of Bigadiç (Balıkesir) Bentonite Deposits and the Mobility of Major, Trace and Rare Earth Elements During Bentonitization}

\begin{abstract}
Acidic volcanism, which is dacite, rhyodacite and rhyolite in composition and their pyroclastics became very active during early Miocene in the Bigadiç volcano-sedimentary succession. Numerous bentonite deposits, associated with these volcanic rocks are found in the Bigadiç area. In the studied area, mineralogical and chemical features of the Bigadiç bentonite deposits, which were derived in-situ alteration of glassy-crystal tuffs, have been determined. In addition, behaviour of major, trace and, rare earth elements (REE) were examined during bentonitization. XRD studies showed that Camontmorillonite is the main clay mineral in these deposits. Plagioclase, sanidine, biotite, calcite, $\mathrm{Ca}$ dolomite, quartz, cristobalite, opal-CT, illite, kaolinite and alünite are the common impurities. Wholerock chemical analyses of samples of bentonites; represent a net gain $\mathrm{MgO}, \mathrm{CaO}, \mathrm{H}_{2} \mathrm{O}, \mathrm{TiO}_{2}, \mathrm{Fe}_{2} \mathrm{O}_{3}$ and $\mathrm{Al}_{2} \mathrm{O}_{3}$ an a net loss of $\mathrm{Na}_{2} \mathrm{O}, \mathrm{K}_{2} \mathrm{O}$ and $\mathrm{SiO}_{2}$ during bentonitization. Similarly, lossing of $\mathrm{Rb}, \mathrm{Cs}, \mathrm{U}, \mathrm{Y}$ and gaining of $\mathrm{Zn}, \mathrm{Sr}, \mathrm{Zr}$ have been determined.
\end{abstract}

\footnotetext{
*Yazışmaların yapılacağı yazar: Fazlı ÇOBAN, Balıkesir Üniversitesi, Mühendislik-Mimarlık Fakültesi, Jeoloji Mühendisliği Bölümü, Balıkesir.fcoban@balikesir.edu.tr
} 
Bigadiç (Balıkesir) Bentonit Yataklarının Mineraloji ve Jeokimyası ve Bentonitleşme Sırasındaki Ana, Eser ve Nadir Toprak Elementlerinin Mobilizasyonu

On the other hand, high rare earth elements (HREE) are relative depleted during bentonitization and light rare earth elements (LREE) are enriched in bentonites.

Keywords: Bigadiç (Balıkesir), Bentonitization, Element mobilization.

\section{GíRiş}

$\mathrm{Bu}$ çalışmada; erken Miyosen yaşlı Bigadiç volkano-sedimanter havzasında volkanik ve gölsel birimler ile ilişkili olan; 1:25.000 ölçekli Balıkesir

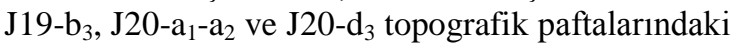
Yeniköy, Dereköy, Çekirdekli ve Kargın bentonitlerinin mineralojik-jeokimyasal özellikleri belirlenerek, bentonitleşme sırasındaki element hareketliliği incelenmiştir.

\section{CALISMA YÖNTEMLERI}

İnceleme alanındaki bentonitlerden alınan 15 adet örnek üzerinde X-Işınları Difraksiyonu (tüm kayaç ve kil boyutu) ve kimyasal analiz incelemeleri yapılmıştır. XRD incelemeleri kil minerallerinin ve diğer kil boyutu minerallerin tayini için yapılmıştır. Kimyasal analizler ile bentonitlerin kimyasal bileşimleri ortaya konmuştur. X-1şınları incelemelerinin bir kısmı daha önceki çalışmalardan derlenmiş [1-4]; bentonitler ile ilişkili diğer XRD incelemeleri Afyon Kocatepe Üniversitesi, Teknoloji Araştırma Merkezi (TUAM)'ndeki Shimadzu XRD-6000 model $\mathrm{X}-1$ şını difraktometre kayıt cihazı ile yapılmıştır.

Kil boyutu ayrımı yapılan örneklerden normal, etilen glikollü ve $550^{\circ} \mathrm{C}$ 'de firınlanmış kayıtlar alınmıştır [5]. Tüm kayaç ana element, eser element ve nadir toprak element (REE) analizleri ACME Analytical Laboratories Ltd. (Kanada) laboratuarlarında yapılmıştır. Ana element içerikleri; $200 \mathrm{~g}$ örneğin 1,5 g LiBO 2 ile eritilerek, \%5'lik $100 \mathrm{MLS} \mathrm{HNO}_{3}$ içinde çözülmesi ile elde edilen çözeltiden ICP spektroskopisi ile tayin edilmiş ve tayinler sırasında SO-15/CSA standardı kullanılmıştır [6]. Eser elementlerin bir kısmı ve nadir toprak element (REE) tayinleri, SO-15 standardı kullanılarak ICP-MS ile yapılmıştır.

\section{JEOLOJI}

Ekonomik bor yatakları içeren Bigadiç bor havzasındaki bentonit oluşumları erken Miyosen yaşlı volkanik ve gölsel birimlerden oluşan Bigadiç volkano-sedimenter serisinin değişik düzeylerinde bulunur. Volkanik birimler bazaltriyolit arasında bileşim değişimleri gösteren lavlar ve bunların piroklastiklerinden oluşur ve karbonatlı, killi ve silisli tortullardan oluşan gölsel birimler ile ardalanmalıdır [7]. Gölsel birimler alttan üste doğru;"alt kireçtaşı birimi, alt tüf birimi, alt boratlı birim, üst tüf birimi ve üst boratlı birim" olarak adlandırılmıştır [8]. Yeniköy ve Dereköy bentonitleri "alt tüf”, Çekirdekli bentoniti "alt boratlı birim", Kargın bentoniti ise "üst boratlı birim" içinde bulunur. Bentonitlerin yer bulduru ve jeolojik haritası Şekil 1'de, ölçülmüş stratigrafik kesitleri ise Şekil 2'de verilmiştir.

\subsection{Kargın Bentoniti}

Balıkesir J20-a paftası, Kargın köyü doğusunda, 04480/60500 koordinatında bulunan bentonit oluşumu; "üst boratlı birim" içindedir. Bigadiç bölgesinde gölsel birimlerin en üst düzeyini oluşturan "üst boratlı birim"; boratlı kiltaşı, tüf, marn ve kireçtaşı ardalanmasından meydana gelir [8]. Kargın bölgesinde dasit-riyodasit bileşimli volkanitler üzerinde uyumsuz olarak bulunan "üst boratlı birim", alt seviyelerinde karbonatlı, kristal tüfler ile başlar. Bu tüfler ile ilişkili olan bentonit, $70-80 \mathrm{~cm}$ kalınlıktaki seviyeler halindedir. Alt kesimlerinde açık yeşilimsi gri, grimsi beyaz renkli olup, üst kesimlere doğru sert, pembe renkli seviyelere dönüşür. Alttan üste doğru, kumlukarbonatl1-manganlı özellik gösteren bentonit; 8-10 m kalınlığında silisifiye kireçtaşları ile örtülü olup, toplam 5-8 m kalınlıktadır (Şekil 2).

\section{2. Çekirdekli Bentoniti}

Balıkesir J20-a paftasında Çekirdekli Köyü 

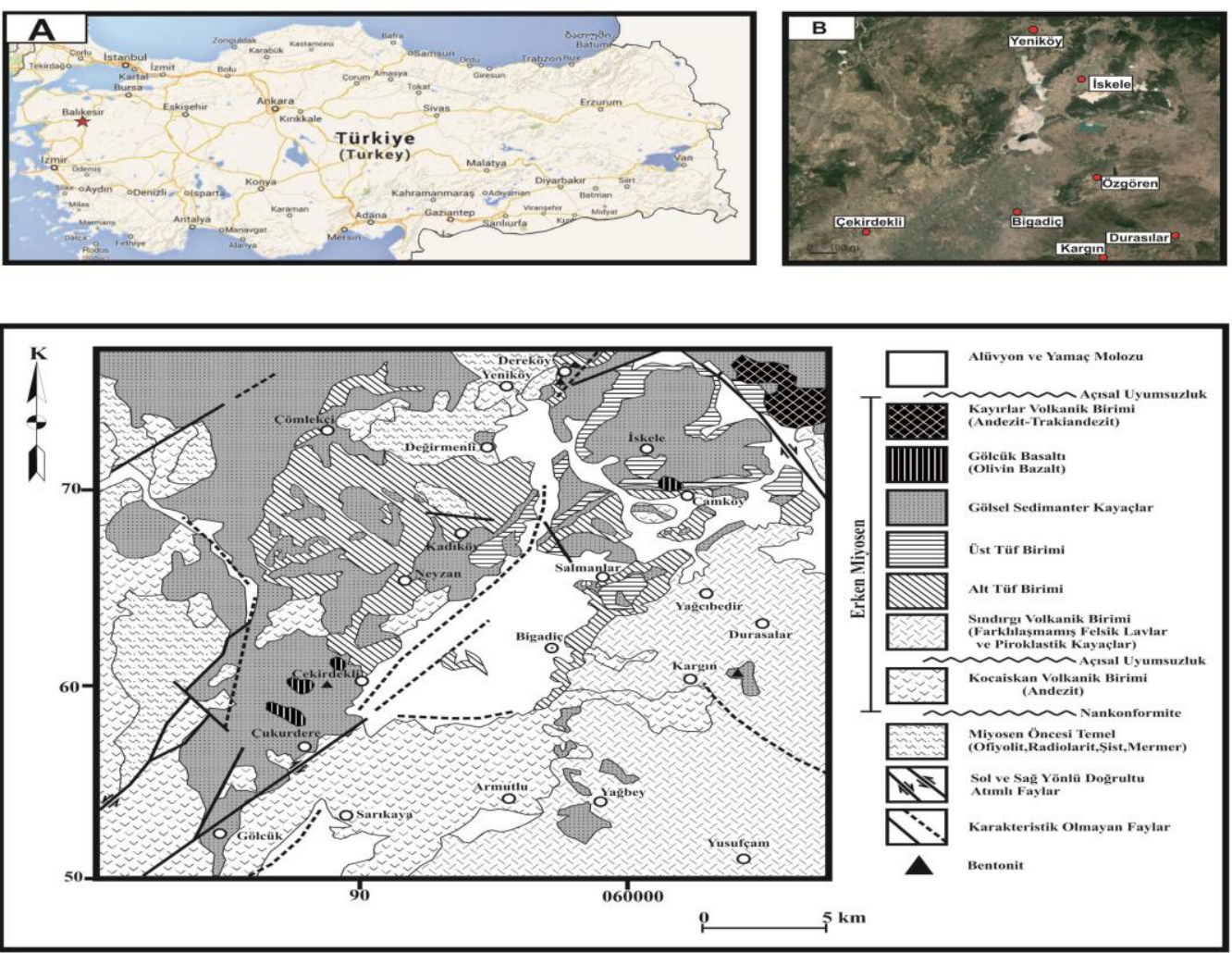

Şekil 1. Bentonitlerin yer bulduru (A, B) ve jeolojik haritası (C) [9]

güneybatısında, 89400/59760 koordinatında bulunan bentonit oluşumu; boratlı kiltaşı, tüf, marn, çörtlü kireçtaşlarından oluşan "alt boratlı birim"in [8] alt seviyelerindeki litik-kristal tüflerle ilişkilidir. Bu tüflerle dereceli geçişli ve kamamercek şekilli beyazımsı-gri plastik bentonitler, alt kesimlerinde 3-10 cm büyüklüğünde volkanik (andezitik) çakıl ve blokları içerir. Üstte; mangan dendritli, $\quad \mathrm{K} 80 \mathrm{D} / 40^{\circ} \mathrm{KB}$ gidişli silisifiye kireçtaşları ile örtülü olan bentonitin kalınlığı 15 metre'dir.

\subsection{Yeniköy Bentoniti}

Yeniköy kuzeydoğusu (Balıkesir J19-b 3 paftası) 99770/76920 koordinatında bulunan bentonit oluşumu; erken Miyosen yaşl1, "alt tüf birimi” [8] içinde bulunur. Riyolitik, dasitik bileşimli, camsal- kristal tüfler ile ilişkili olan bentonit, alttan üste doğru; siyahımsı kahve renkli bentonit, gri plastik bentonit, sarımsı-beyaz kumlu bentonit şeklinde 3 farklı seviye halindedir. Bentonit üzerinde 8-10 m kalınlıkta, ince taneli kristal tüf ve killi karbonat ara katkılı, kumlu kiltaşı bulunur. Tabanında $\mathrm{K} 10 \mathrm{~B} / 80^{\circ} \mathrm{KD}$ gidişli $3 \mathrm{~m}$ kalınlıkta silisifiye zon ile kesilmiş olan bentonitin toplam kalınlığı 20-25 metre'dir (Şekil 2).

\subsection{Dereköy Bentoniti}

Dereköy kuzeyi Hamam sırtı mevkiindeki (Balıkesir-İ20-d 3 paftası; 01798/78059 koordinatında) bentonit oluşumu, "alt tüf birimi" [8] ile ilişkili olup, $\mathrm{K} 60^{\circ} \mathrm{D}$ uzanımlı ve yaklaşık 30 metre kalınlıktadır. Üst kesiminde silisifiye kireçtaşları ile örtülü olan bentonit, altta karbonat 


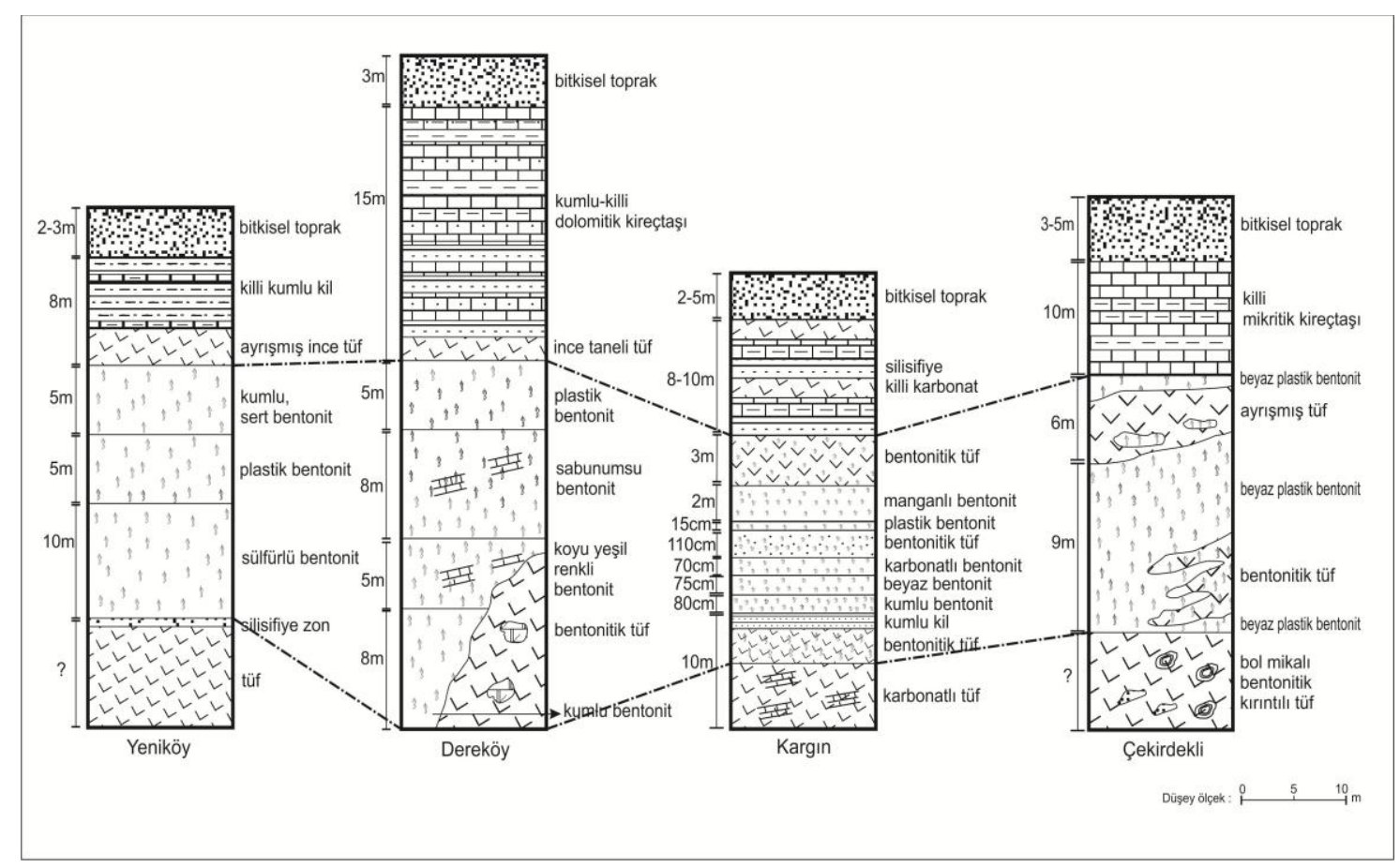

Şekil 2. Bentonitlerin ölçülmüş stratigrafik kesitleri

katkılıdır. Sert, konkoidal kırıklı bentonit altta koyu yeşilimsi gri ve üst kesimlerde ise açık yeşilimsi gri renklidir. Bentonitlerin tabanında dolomitik kireçtaşı yumruları $(3-5 \mathrm{~cm})$ içeren yer yer bentonitleşmiş kristal tüf bulunur (Şekil 2).

\section{MINERALOJI}

\subsection{XRD İncelemeleri}

Bentonitlerin tüm kayaç ve kil boyutu mineralojik bileşimleri XRD incelemeleri ile belirlenmiştir. Buna göre; inceleme konusu bentonitlerdeki yaygın tüm kayaç mineral topluluğu; (smektit + kuvars + feldspat \pm biyotit) şeklinde olup, bu birlikteliğe kristobalit, opal-CT, kaolinit, illit, alünit, kalsit, dolomit ve zeolit eşlik etmektedir. Smektit'in 14,89-15,28 $\AA$ arasında değişen $\mathrm{d}_{001}$ değerleri Ca-smektit'e aittir [5]. İncelenen bentonitlerin kil boyutu XRD kayitlarında smektit'e ait $\mathrm{d}_{001}$ yansımalarının 14,70-16,18 $\AA$ arasında değişim göstermesi smektitlerin Casmektit olduğuna işaret eder. Etilen glikol ile doyurmada $\mathrm{d}_{001}$ yansımalarının 17,88 ile $18,40 \AA$ arasında değiștiği ve $550^{\circ} \mathrm{C}$ 1sıtma sonucunda ise 9,98-10,30 $\AA$ arasında yıkıldığı görülmüştür (Şekil 3). Smektitlerin $d_{(060)}$ ölçümleri yapılmış ve 1,48-1,51 $\AA$ arasında değişen $\mathrm{d}_{(060)}$ değerlerine sahip örneklerin dioktaedral smektit (montmorillonit) olduğu belirlenmiştir [10,11]. Montmorillonit'e eşlik eden diğer kil mineralleri illit ve kaolinit'tir. Diğer taraftan; Dereköy bentoniti hariç diğer bentonitlerdeki kötü kristalli kaolinitler [11] kuvars ve bazen de alünit ile birlikte bulunur. Çekirdekli bentoniti kil boyutu bileşiminde gözlenen opal-CT, (101) yüzeyine ait ve 4,05 $\AA$ ile 4,08 $\AA$ arasında değişen yansımaları ile belirlenmiştir [12]. 4,15 $\AA$ ve 2,53 $\AA$ 'deki ana yansımaları ile belirlenen kristobalitler "yüksek kristobalit" özelliği gösterir [5] ve Yeniköy bentoniti haricindeki tüm bentonitlerde bileşime girmiştir. Dolomitler yüksek kalsiyumlu dolomit (Ca-dolomit) ve kalsitler "düşük $\mathrm{Mg}$ 'lu kalsit" özelliklidir [13,14]. Dereköy bentoniti alt seviyelerinde tespit edilen zeolitler ise kötü kristalli olup, klinoptilolit bileşimlidir. 

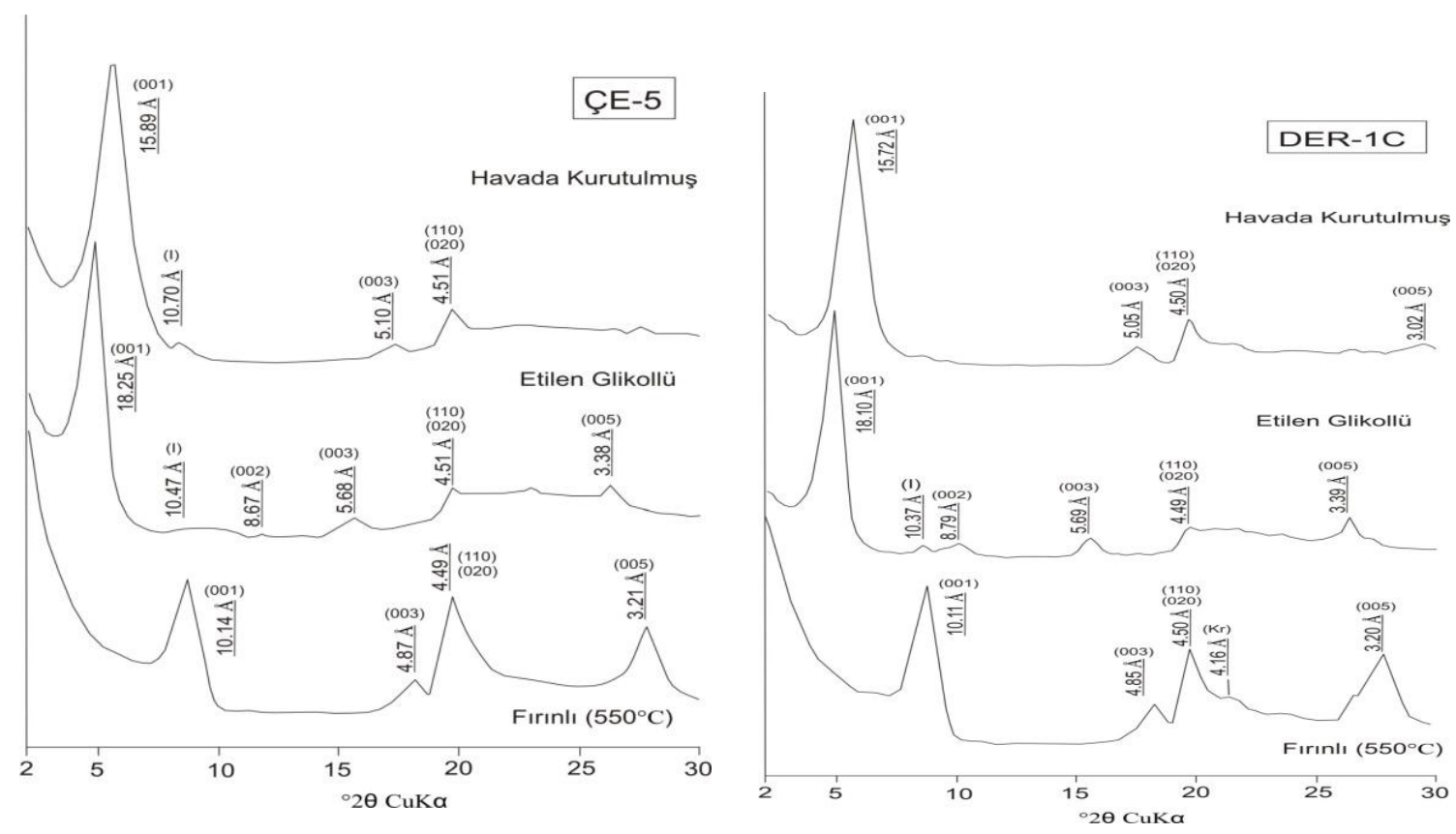

Şekil 3. Bentonitlerin kil boyutu XRD grafikleri (ÇE-5: Çekirdekli, DER1-C: Dereköy bentoniti örnekleri) [1]

Belirlenen minerallerin bentonitlerdeki dağılımları özellikle düşey yönde bazı değişiklikler gösterir. Buna göre; Yeniköy bentonitinin kahverengimsi siyah, gri renkli alt seviyelerinde (montmorillonit + plajiyoklas + kuvars + illit + alünit + kaolinit $)$ şeklinde bir mineral topluluğu gözlenir. Üstteki sarımsı beyaz renkli sert bentonit düzeylerinde montmorillonit yanında özellikle Ca-dolomit ve düşük Mg'lu kalsit belirlenmiştir. Yeniköy bentonitinde alttan üste doğru kalsit ve dolomit mineralleri fazlalaşırken, illit azalır. Benzer olarak alünit alttaki siyahımsı-gri seviyelerde kötü kristalli kaolinit ile birliktedir. Yeniköy bentoniti üst seviyeleri dolomitli bentonit olarak adlandırılabilecek özellikler gösterir. Yeniköy bentonitine yakın olan ve aynı jeolojik birim (alt tüf birimi) içinde bulunan Dereköy bentonitindeki genel mineral parajenezi; (montmorillonit + kuvars + kristobalit + dolomit \pm sanidin \pm kalsit \pm zeolit $)$ şeklindedir. Zeolitler alt kesimlerdeki kumlu bentonit düzeylerinde gözlenir ve klinoptilolit türdedir. Özellikle alt seviyelerde yoğun olarak gözlenen kristobalit üst seviyelere geçişte bileșimde daha az görülür.

Dereköy bentonitinin alttaki kumlu bentonit seviyelerinde bileşime giren kötü kristalli sanidin, Dereköy bentoniti ana kayasının Yeniköy bentoniti ana kayasından farklı olabileceğini işaret etmektedir. Kargın bentoniti alt seviyelerindeki kumlu bentonitlerde (montmorillonit + kuvars + plajiyoklas) şeklinde bir mineral topluluğu, karbonatlı düzeylerde (montmorillonit + dolomit \pm kalsit); üst seviyelerdeki çatlaklarında bol demirmangan oksit sıvamaları içeren manganlı bentonitlerde ise (montmorillonit + kuvars + kaolinit \pm kristobalit) egemendir. Çekirdekli bentoniti alt seviyelerindeki ayrışmış mika (biyotit) üst kesimlerde gözlenmez. Özellikle kuvars, (yüksek) kristobalit ve opal-CT her düzeyde tespit edilmiştir. Kötü kristalli kaolinitler, kuvars ile birlikte özellikle alt seviyelerde bileşime girmiştir. Alt seviyelerde belirlenen illite ait XRD kayıtlarında (001) piklerinin genellikle basık ve $11 \AA$ tarafına doğru asimetrik özellik göstermesi mikaların illit-smektit ve illite dönüşümünü 
gösterir. Bentonitlerin mineralojik bileşimleri aşağıdaki gibidir.

Yeniköy:

Montmorillonit+plajiyoklas+kuvars+illit+kalsit+ dolomit \pm kaolinit \pm alünit

Dereköy:

Montmorillonit+kuvars+kristobalit+dolomit \pm sanidin \pm kalsit \pm zeolit

Kargin:

Montmorillonit+kuvars+kristobalit+plajiyoklas+ dolomit \pm kaolinit \pm alünit

Çekirdekli:

Montmorillonit+kuvars+kristobalit+opalCT+ plajiyoklas \pm illit \pm kaolinit \pm mika

\section{JEOKIMYA}

Bentonitlerden alınan 13 adet örneğin ana, eser ve nadir toprak element kimyasal analizleri yapılarak bentonitleşme sırasındaki element hareketliliği incelenmiştir. Ana kaya ve bentonit örneklerine ait ana, eser, nadir toprak element içerikleri Çizelge 1'de verilmiştir [8].

\subsection{Ana Elementler}

İnceleme konusu bentonitlerin ana element kimyasal analiz sonuçları, ana element ikili değişim diyagramları (Şekil 4) ve ana kayaca göre normalize edilmiş ana element içerikleri (Şekil 7) incelendiğinde; bentonitleşme sırasında ilerleyen alterasyona bağgli olarak $\mathrm{Al}_{2} \mathrm{O}_{3}, \mathrm{MgO}, \mathrm{Fe}_{2} \mathrm{O}_{3}, \mathrm{CaO}$ ve $\mathrm{TiO}_{2}$ kazançları; $\mathrm{SiO}_{2}, \mathrm{Na}_{2} \mathrm{O}$ ve $\mathrm{K}_{2} \mathrm{O}$ kayıpları meydana gelmiştir. $\mathrm{MgO}$ en fazla zenginleşme göstermiş, bunu sırasıyla $\mathrm{CaO}, \mathrm{Fe}_{2} \mathrm{O}_{3}, \mathrm{TiO}_{2}$ ve $\mathrm{Al}_{2} \mathrm{O}_{3}$ izlemiştir. Maksimum $\mathrm{MgO}$ zenginleşmesi ve maksimum $\mathrm{Na}_{2} \mathrm{O}$ kaybı Dereköy bentonitinde gerçekleşirken, Çekirdekli bentonitinde $\mathrm{Na}_{2} \mathrm{O}$ ve $\mathrm{K}_{2} \mathrm{O}$ kayıpları diğerlerine göre daha azdır. En fazla kayıp/kazanç Dereköy bentonitinde gerçekleşmiştir (Şekil 5). Diğer taraftan ilerleyen alterasyon ile birlikte oluşan sulu alüminyum silikat mineralleri $\mathrm{H}_{2} \mathrm{O}$ değerlerinin artmasını sağlamıştır.

Ana kayadan bentonite dönüşüm sırasında hareketsiz (immobile) davranan Al'un bentonitin zenginleşmesi alterasyon esnasında erimeyen kalıntı malzemede birikme (yerinde zenginleşme) yoluyla olmaktadır [15,16]. Ana kayacın $\mathrm{Al}_{2} \mathrm{O}_{3}$ içeriği ile alterasyona bağlı olarak içerikleri değişen diğer ana element içerikleri arasındaki ikili değişim diyagramları, bentonitteki element kaybı ve/veya zenginleşmesi ile ilgili bilgi verir [14]. İncelenen bentonitlere ait $\mathrm{Al}_{2} \mathrm{O}_{3}-\mathrm{MgO}$, $\mathrm{Al}_{2} \mathrm{O}_{3}-\mathrm{CaO}, \quad \mathrm{Al}_{2} \mathrm{O}_{3}-\mathrm{Fe}_{2} \mathrm{O}_{3}$ ve $\mathrm{Al}_{2} \mathrm{O}_{3}-\mathrm{TiO}_{2}$ diyagramlarinda $\mathrm{MgO}, \mathrm{CaO}, \mathrm{Fe}_{2} \mathrm{O}_{3}$ ve $\mathrm{TiO}_{2}$ ' in $\mathrm{Al}_{2} \mathrm{O}_{3}$ 'e göre pozitif lineer artışının, ilgili elementlerin hareketsiz olduğunu belirten (yerinde zenginleşme) orijinden geçen pozitif lineer bir doğru şeklinde olmadığı görülmektedir (Şekil 4). Benzer olarak $\mathrm{Al}_{2} \mathrm{O}_{3}-\mathrm{SiO}_{2}, \mathrm{Al}_{2} \mathrm{O}_{3}-\mathrm{Na}_{2} \mathrm{O}, \mathrm{Al}_{2} \mathrm{O}_{3}$ $\mathrm{K}_{2} \mathrm{O}$ ikili değişim diyagramlarında $\operatorname{artan} \mathrm{Al}_{2} \mathrm{O}_{3}$ değerlerine karşılı; $\quad \mathrm{SiO}_{2}, \quad \mathrm{Na}_{2} \mathrm{O}, \quad \mathrm{K}_{2} \mathrm{O}$ azalmaktadır. İkili ana element değişim diyagramlarına göre bentonitleşme sırasında; $\mathrm{SiO}_{2}$, $\mathrm{Na}_{2} \mathrm{O}$ ve $\mathrm{K}_{2} \mathrm{O}$ kayıpları, buna karşın diş kaynaklı $\mathrm{MgO}, \mathrm{Fe}_{2} \mathrm{O}_{3}, \mathrm{CaO}$ ve $\mathrm{TiO}_{2}$ zenginleşmeleri meydana gelmiş̧ir.

\subsection{Eser Elementler}

İnceleme konusu bentonit örneklerine ait bazı eser element analiz sonuçları Çizelge 1'de, ana kayaca göre normalize edilmiş eser element değişimleri Şekil 6'da verilmiştir. Riyolitik camın bentonite dönüşümünde $\mathrm{Cs}, \mathrm{Rb}, \mathrm{U}$ ve $\mathrm{Zr}$ alterasyonun ilk evrelerinde kayba uğrar, $\mathrm{Sr}, \mathrm{Sc}, \mathrm{Cr}$ ve Co farklı yollarla bentonitte zenginleşir [16]. Eser elementlerin bentonitlerdeki değişimlerine bakıldığında, Yeniköy, Kargın ve Çekirdekli bentonitlerinde $\mathrm{Cs}, \mathrm{Rb}$ ve U; Dereköy bentonitinde ise $\mathrm{Cs}, \mathrm{Rb}, \mathrm{U}$ ve $\mathrm{Y}$ alterasyon ile birlikte kayba uğramış, tüm bentonitlerde $\mathrm{Zr}, \quad \mathrm{Sr}$ ve $\mathrm{Zn}$ zenginleşmiştir. $\mathrm{Rb}, \mathrm{Cs}, \mathrm{U}$ ve $\mathrm{Y}$ maksimum kayba uğramış, $\mathrm{Zn}$ en fazla zenginleşmiştir. $\mathrm{Ga}, \mathrm{Hf}, \mathrm{Nb}$, $\mathrm{Ta}, \mathrm{Yb}, \mathrm{Th}$ 'un ise hareketsiz davrandıkları söylenebilir (Şekil 6). Bentonite dönüşüm sirasinda alkaliler ile beraber davranan $\mathrm{Cs}$ ve $\mathrm{Rb}$; Yeniköy ve Dereköy bentonitinde ana kayadan hızla çözünerek hareketli (mobile) olmuş ve taşınarak bentonitte birikmiştir. Altere malzemedeki U zenginleşmesi çoğunlukla ikincil silis ve sulu Fe-Mn oksitlerin adsorbsiyonu yoluyla gerçekleşir. Ayrıca, riyolitik volkanik camın çözünmesi sırasında yükseltgen ortamda alkali çözeltiler yoluyla altere malzemede 
Çizelge 1. Bentonitlerin ve ana kaya (T)'nın ana, eser ve nadir toprak element içerikleri $\left(\mathrm{KAR}_{1-3}\right.$ : Kargın, ÇE ${ }_{1-3}$ : Çekirdekli, $\mathrm{DE}_{1-3}$ : Dereköy, $\mathrm{YE}_{1-4}$ : Yeniköy örnekleri)

\begin{tabular}{|c|c|c|c|c|c|c|c|c|c|c|}
\hline & \multicolumn{10}{|c|}{ Ana Elementler(\% Ağırlık) } \\
\hline & $\mathrm{SiO}_{2}$ & $\overline{\mathbf{A l}_{2} \mathbf{O}_{3}}$ & $\mathrm{Fe}_{2} \mathrm{O}_{3}$ & MgO & $\mathrm{CaO}$ & $\mathrm{Na}_{2} \mathrm{O}$ & $\mathrm{K}_{2} \mathrm{O}$ & $\mathrm{TiO}_{2}$ & Ateş Kaybı & Toplam \\
\hline KAR1 & 58,8 & 16,29 & 1,8 & 6,52 & 2,15 & 0,12 & 0,53 & 0,08 & 13,5 & 99,79 \\
\hline KAR2 & 66,59 & 13,2 & 1,27 & 4,01 & 1,73 & 0,08 & 0,34 & 0,05 & 12,6 & 99,87 \\
\hline KAR3 & 62,82 & 16,18 & 1,74 & 4,85 & 2,1 & 0,08 & 0,44 & 0,05 & 13,76 & 102,02 \\
\hline ÇE1 & 58,31 & 17,95 & 1,6 & 4,49 & 1,82 & 0,15 & 0,53 & 0,07 & 14,9 & 99,82 \\
\hline ÇE2 & 58,07 & 15,92 & 1,75 & $\overline{5,61}$ & 2,65 & 0,11 & 0,33 & 0,08 & 15,2 & 99,72 \\
\hline ÇE3 & 61,44 & 14,55 & 1,56 & 4 & 2,05 & 0,49 & 1,98 & 0,09 & 13,6 & 99,76 \\
\hline DE1 & 55,41 & 15,37 & 1,62 & 6,89 & 2,75 & 0,06 & 0,32 & 0,08 & 17,3 & 99,8 \\
\hline DE2 & 56,08 & 15,86 & 1,04 & 6,14 & 2,07 & 0,04 & 0,51 & 0,08 & 17,3 & 99,12 \\
\hline DE3 & 55,12 & 16,02 & 1,43 & 5,89 & 2,81 & 0,08 & 0,54 & 0,09 & 17,92 & 99,9 \\
\hline YE1 & 52,66 & 17,04 & 1,32 & 4,36 & 1,72 & 0,1 & 0,35 & 0,1 & 22,2 & 99,85 \\
\hline YE2 & 51,81 & 18,87 & 1,34 & 3,51 & 1,53 & 0,09 & 0,4 & 0,12 & 22,2 & 99,87 \\
\hline YE3 & 52,58 & 18,33 & 1,62 & 3,69 & 1,63 & 0,1 & 0,53 & 0,13 & 21 & 99,61 \\
\hline YE4 & 50,88 & 18,09 & 1,02 & 4,67 & 2 & 0,07 & 0,4 & 0,08 & 22,7 & 99,91 \\
\hline $\mathbf{T}$ & 68,58 & 12,26 & 1,17 & 0,79 & 0,87 & 1,39 & 5,53 & 0,07 & 9,1 & 99,76 \\
\hline
\end{tabular}

Eser Elementler (ppm)

\begin{tabular}{|c|c|c|c|c|c|c|c|c|c|c|c|c|}
\hline & Cs & $\mathbf{R b}$ & Ga & Hf & $\mathbf{N b}$ & $\mathbf{T a}$ & Th & $\mathbf{Y}$ & $\mathbf{Z r}$ & $\mathrm{Sr}$ & $\mathbf{U}$ & $\mathbf{Z n}$ \\
\hline KAR1 & 17,8 & 24,5 & 18,1 & 5,4 & 17,9 & 2 & 38,4 & 31 & 145,7 & 172,9 & 2,7 & 35 \\
\hline KAR2 & 81,3 & 34,2 & 14,3 & 4,4 & 16,7 & 1,4 & 30,8 & 26,7 & 108,9 & 150,2 & 2,9 & 20 \\
\hline KAR3 & 45,2 & 28,6 & 15,2 & 4,6 & 16,9 & 1,7 & 32,5 & 28,2 & 109,8 & 162 & 2,7 & 28 \\
\hline ÇE1 & 7 & 13,5 & 21,1 & 7,5 & 29,4 & 3,1 & 51,5 & 33,9 & 150,6 & 174,5 & 8,5 & 29 \\
\hline ÇE2 & 14,1 & 21 & 18,8 & 5,3 & 22,3 & 2,5 & 40,6 & 26,1 & 117,1 & 116 & 1,4 & 34 \\
\hline ÇE3 & 80,9 & 281,7 & 16,4 & 4,1 & 21,7 & 1,8 & 40,8 & 21,9 & 105,2 & 147,6 & 3,7 & 22 \\
\hline DE1 & 6,9 & 15,2 & 17,1 & 4,5 & 24 & 2,3 & 39 & 13,3 & 113,5 & 126,3 & 2,6 & 22 \\
\hline DE2 & 5,9 & 14,8 & 16,8 & 3,9 & 22 & 2,1 & 44 & 13,8 & 128,4 & 130,6 & 2,1 & 24 \\
\hline DE3 & 6,2 & 14,9 & 16,6 & 4,2 & 25 & 2,2 & 45 & 14,1 & 125,6 & 128,6 & 2,4 & 22 \\
\hline YE1 & 5,6 & 9,6 & 19,2 & 5,7 & 24,2 & 2,6 & 44,5 & 35,7 & 131,7 & 132,7 & 6,5 & 14 \\
\hline YE2 & 5,6 & 12,6 & 21,3 & 6,6 & 24,8 & 2,7 & 52,8 & 31,2 & 161 & 134,8 & 8,3 & 39 \\
\hline YE3 & 6,4 & 15,4 & 21,5 & 6,6 & 21,6 & 2,4 & 47,8 & 32,8 & 188,5 & 155,9 & 8,3 & 51 \\
\hline YE4 & 5 & 14,8 & 21,9 & 6,1 & 27,7 & 3 & 48,8 & 26,1 & 128,9 & 101,2 & 4 & 83 \\
\hline $\mathbf{T}$ & 80,1 & 641,2 & 14,8 & 4,5 & 17,7 & 1,8 & 32 & 30,5 & 96 & 83,7 & 9,5 & 9 \\
\hline
\end{tabular}


Bigadiç (Balıkesir) Bentonit Yataklarının Mineraloji ve Jeokimyası ve Bentonitleşme Sırasındaki Ana, Eser ve Nadir Toprak Elementlerinin Mobilizasyonu

\section{Çizelge 1'in devamı}

\begin{tabular}{|c|c|c|c|c|c|c|c|c|c|c|c|c|c|c|}
\hline & \multicolumn{14}{|c|}{ Nadir Toprak Elementleri (ppm) } \\
\hline & $\mathbf{L a}$ & $\mathrm{Ce}$ & Pr & Nd & $\mathbf{S m}$ & Eu & Gd & $\mathbf{T b}$ & Dy & Ho & $\mathbf{E r}$ & $\mathbf{T m}$ & $\mathbf{Y b}$ & $\overline{\mathbf{L u}}$ \\
\hline $\mathbf{K A R}_{1}$ & 45,4 & 87,9 & 9,65 & 30,9 & 6,05 & 0,55 & 5,47 & 0,92 & 5,81 & 1,01 & 3,03 & 0,51 & 3,21 & 0,5 \\
\hline $\mathrm{KAR}_{2}$ & 35 & 67,5 & 7,29 & 23,2 & 4,77 & 0,42 & 4,42 & 0,78 & 4,72 & 0,82 & 2,57 & 0,42 & 2,88 & $\overline{0,41}$ \\
\hline $\mathrm{KAR}_{3}$ & 38,4 & 75,2 & 7,48 & 25,4 & 5,06 & 0,46 & 4,81 & 0,85 & 4,86 & 0,96 & 2,64 & 0,4 & 2,91 & 0,42 \\
\hline $\mathbf{C C}_{1}$ & 33,1 & 67,1 & 7,77 & 26,1 & 6,37 & 0,35 & 6,17 & 1,09 & 6,19 & 1,12 & 3,32 & 0,53 & 3,5 & $\overline{0,53}$ \\
\hline $\mathbf{C C}_{2}$ & 33,4 & 77 & 7,49 & 24 & 5,45 & 0,33 & 5,09 & 0,85 & 5,11 & 0,84 & 2,62 & 0,42 & 2,74 & 0,41 \\
\hline $\mathrm{CCE}_{3}$ & 30,2 & 49,8 & 7,05 & 26,2 & 4,94 & 0,23 & 4,03 & 0,69 & 3,45 & 0,68 & 2,25 & 0,3 & 2,18 & 0,32 \\
\hline$\overline{\mathrm{DE}_{1}}$ & 21,2 & 45,4 & 5,02 & 16,4 & 3,44 & 0,23 & 2,83 & 0,48 & 2,76 & 0,49 & 1,62 & 0,28 & 2,03 & 0,33 \\
\hline$\overline{\mathrm{DE}_{2}}$ & 20,8 & 44,9 & 5,01 & 15,9 & 3,41 & 0,22 & 2,75 & 0,42 & 2,81 & 0,45 & 1,64 & 0,22 & 2,08 & 0,39 \\
\hline $\mathrm{DE}_{3}$ & 21,3 & 46,8 & 5,04 & 16,3 & 3,4 & 0,24 & 2,81 & 0,42 & 2,8 & 0,48 & 1,68 & 0,24 & 2,11 & 0,4 \\
\hline $\mathbf{Y E}_{1}$ & 30,8 & 60,3 & 7,11 & 26,8 & 6,3 & 0,3 & 5,27 & 1,08 & 5,67 & 1,15 & 3,43 & 0,55 & 3,55 & $\overline{0,59}$ \\
\hline $\mathbf{Y E}_{2}$ & 61,1 & 110,3 & 11,77 & 40 & 8,7 & 0,58 & 6,22 & 1,21 & 6,52 & 1,2 & 3,26 & 0,49 & 3,32 & $\overline{0,47}$ \\
\hline $\mathbf{Y E}_{3}$ & 52,2 & 90,6 & 9,95 & 31,9 & 7 & 0,46 & 5,89 & 1,16 & 6,19 & 1,15 & 3,18 & 0,47 & 2,72 & 0,44 \\
\hline $\mathbf{Y E}_{4}$ & 28,7 & 58,3 & 6,98 & 25,8 & 6,9 & 0,3 & 5,64 & 1,07 & 5,57 & 1,1 & 2,8 & 0,42 & 3,03 & 0,45 \\
\hline $\mathbf{T}$ & 28,9 & 56,7 & 6,29 & 22,6 & 5 & 0,27 & 4,37 & 0,84 & 4,38 & 0,98 & 2,99 & 0,47 & 3,05 & 0,51 \\
\hline
\end{tabular}

U zenginleşir [16,17]. Dereköy ve Kargın bentonitlerinde alterasyon ile birlikte hizlı bir U göçü gerçekleşerek U sistemden taşınmış; Yeniköy ve Çekirdekli bentonitlerinde $U$ daha yavaş çözünmüş ve Yeniköy bentonitinde en az tüketilmiştir. Diğer taraftan ignimbritlerin bentonite alterasyonu sırasında Zr kalıntı olarak bentonit içinde zenginleşebilir [18]. İncelenen örneklerdeki küçük $\mathrm{Zr}$ zenginleşmeleri bentonitleşme sırasında erimeyen kalıntı mineral (biyotit) yoluyla ve $\mathrm{Zn}$ zenginleşmeleri ise yapısal birleşme yoluyla (dış kaynaklı) gerçekleşmiş olmalıdır. Alterasyon sürecinde kayba uğrayan Y ve ağır nadir toprak elementlerinin (HREE) durumunu yansıtır [19]. Y özellikle Dereköy bentonitinde ağır nadir toprak elementleri ile birlikte hareket etmiş ve maksimum kayba uğramıştır.

\subsection{Nadir Toprak Elementleri}

Volkanik camdan smektite dönüşümünde Ağır Nadir Toprak Elementleri (HRRE), Hafif Nadir Toprak Elementleri (LREE)'ne göre daha zor mobilize olur ve ilerleyen alterasyonla birlikte altere üründeki REE içerikleri değişiklik gösterir
[16]. Ana kayaca göre normalize edilmiş Nadir Toprak Elementlerinin inceleme konusu bentonitlerdeki dağılımına bakıldığında, Dereköy bentoniti hariç diğer bentonitlerde Hafif Nadir Toprak Elementleri (LREE)'nde bir zenginleşme meydana gelmiştir (Şekil 7).

Yeniköy bentonitinde siyahımsı kahve-gri renkli alt seviyelerin $\left(\mathrm{YE}_{2-3}\right)$ LREE içerikleri üstteki açık sarımsı seviyelerin LREE içeriklerinden daha yüksektir. Alkali koşullarda duraylı kalabilen Ağır Nadir Toprak Elementleri (HREE) Dereköy bentonitinde tüketilmiş, Kargın ve Çekirdekli bentonitlerinde alt seviyelerdeki örneklerde çok az, Yeniköy bentonitinde ise yine alt seviye örneklerinde daha fazla (özellikle Gd, Tb, Dy ve Ho) zenginleşmiştir. Sicaklığın yüksek olduğu alterasyon şartlarında altere üründe $\mathrm{Eu}^{+2}$ zenginleşmesi meydana gelebilir [20,21]. Benzer olarak andezitik volkaniklerin bentonite dönüşümü sırasında ilerleyen alterasyona bağlı olarak plajiyoklasların smektite replase olması ile altere üründe Eu zenginleşir [18-22]. İnceleme konusu tüm bentonitlerde $\mathrm{Eu}$ zenginleşmesi meydana gelmiş olup, Kargın bentonitinde bu zenginleşme en fazladır. Diğer taraftan; Yeniköy bentonitinde 

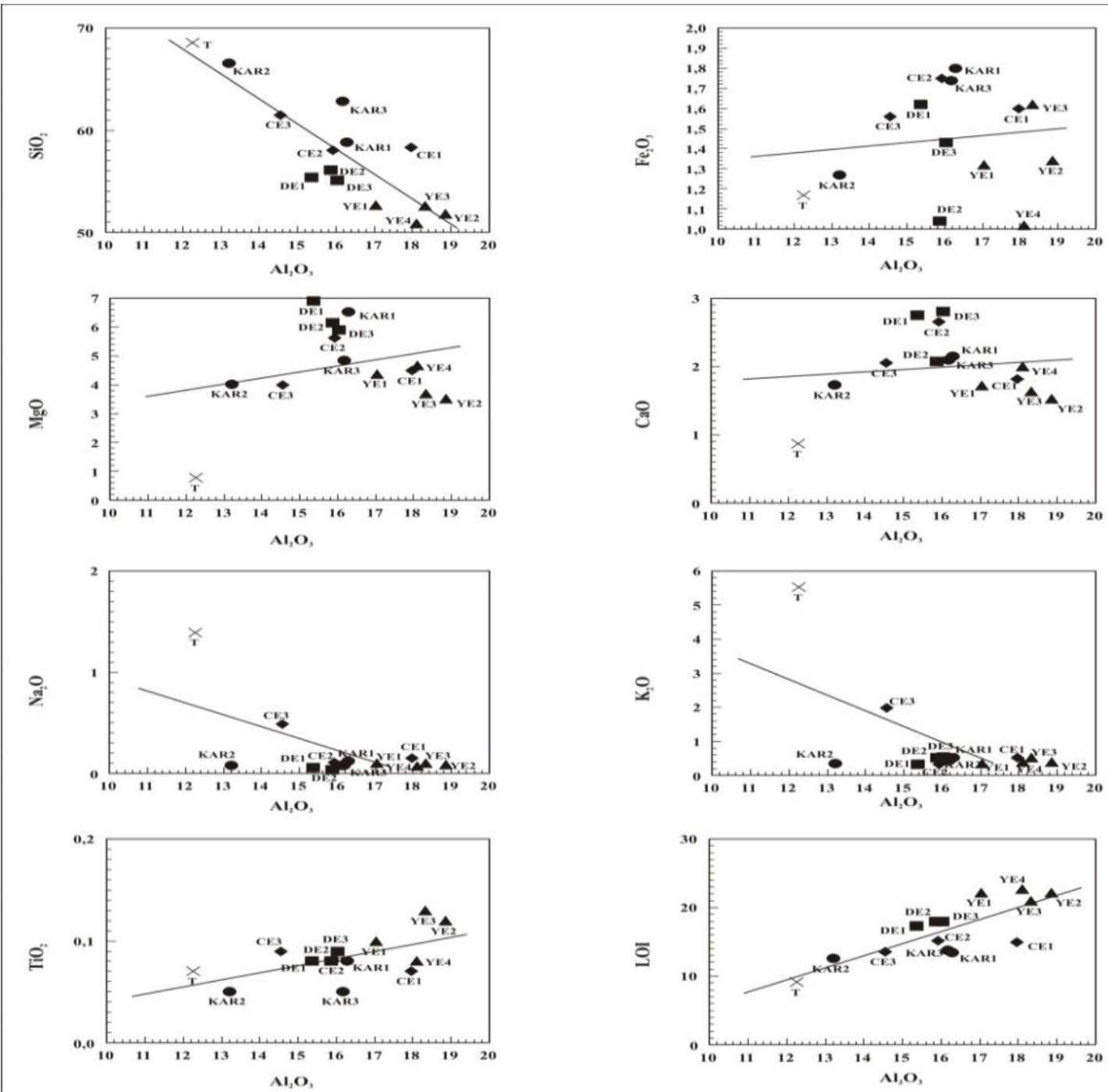

Şekil 4. $\mathrm{Al}_{2} \mathrm{O}_{3}-\mathrm{SiO}_{2}, \mathrm{Fe}_{2} \mathrm{O}_{3}, \mathrm{MgO}, \mathrm{CaO}, \mathrm{Na}_{2} \mathrm{O}, \mathrm{K}_{2} \mathrm{O}, \mathrm{TiO}_{2}$ ve $\mathrm{H}_{2} \mathrm{O}$ diyagramları. $\mathrm{x}$ : Ana kaya

alt seviyelerdeki $\left(\mathrm{YE}_{2-3}\right) \mathrm{Eu}$ zenginleşmesi üst seviyelere göre daha fazladır. Bentonitlerin oluşumuna neden olan ana kaya türlerinin belirlenmesi için kullanılan; $\mathrm{Zr} / \mathrm{TiO}_{2}-\mathrm{Nb} / \mathrm{Y}$ [23] diyagramında Dereköy bentoniti ana kayasının trakitik, Yeniköy ve Kargın bentonitlerinin ana kayalarının riyolitik; Çekirdekli bentonitinin ana kayasının (kısmen) trakiandezitik özellikte olduğu belirlenmiştir (Şekil 8).
REE desenlerindeki farklılık ana kayaların değişik olduğunu destekler özellikler gösterir (Şekil 7).

\section{SONUÇLAR VE TARTIŞMA}

Erken Miyosen yaşlı Bigadiç volkano-sedimanter serisi içinde değişik bileşimli tüflerin alterasyonu ile bentonitler oluşmuştur. Düzensiz mercek ve kama şekilli geometriye sahip bentonitler 
Bigadiç (Balıkesir) Bentonit Yataklarının Mineraloji ve Jeokimyası ve Bentonitleşme Strasındaki Ana, Eser ve Nadir Toprak Elementlerinin Mobilizasyonu

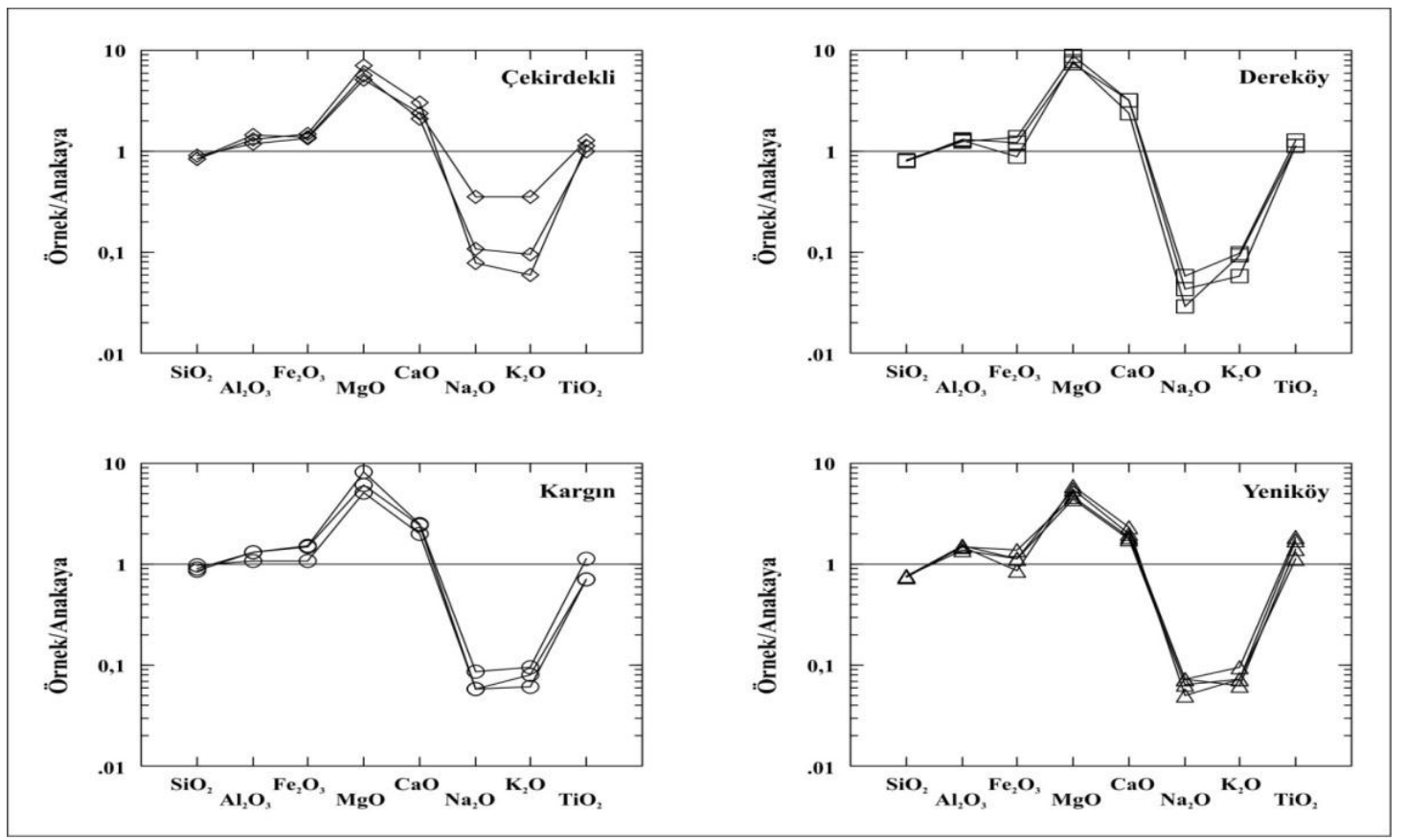

Şekil 5. Bentonite dönüşüm sırasında ana elementlerin değişim diyagramı

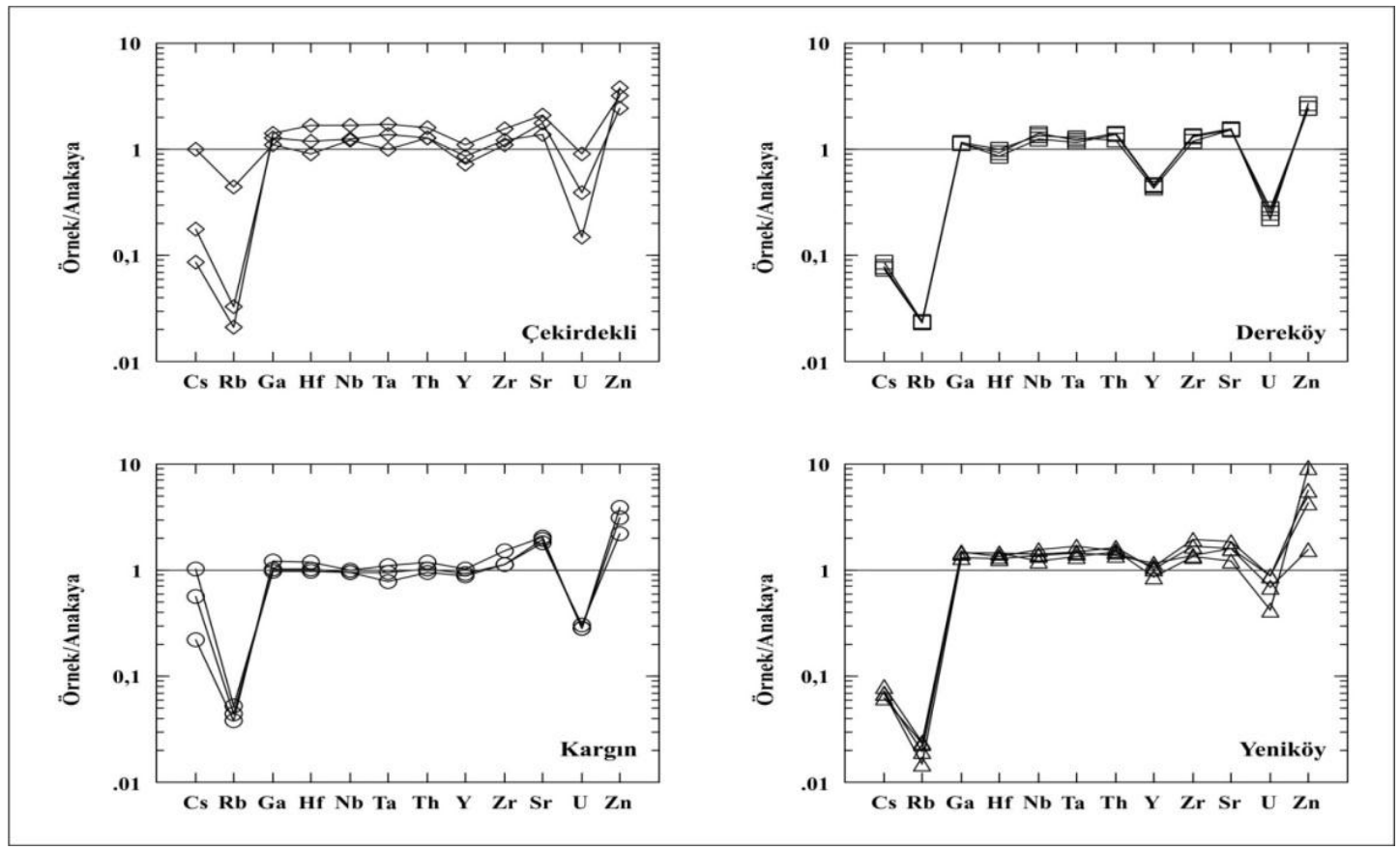

Şekil 6. Bentonite dönüşüm sırasında bazı eser elementlerin değişim diyagramı 


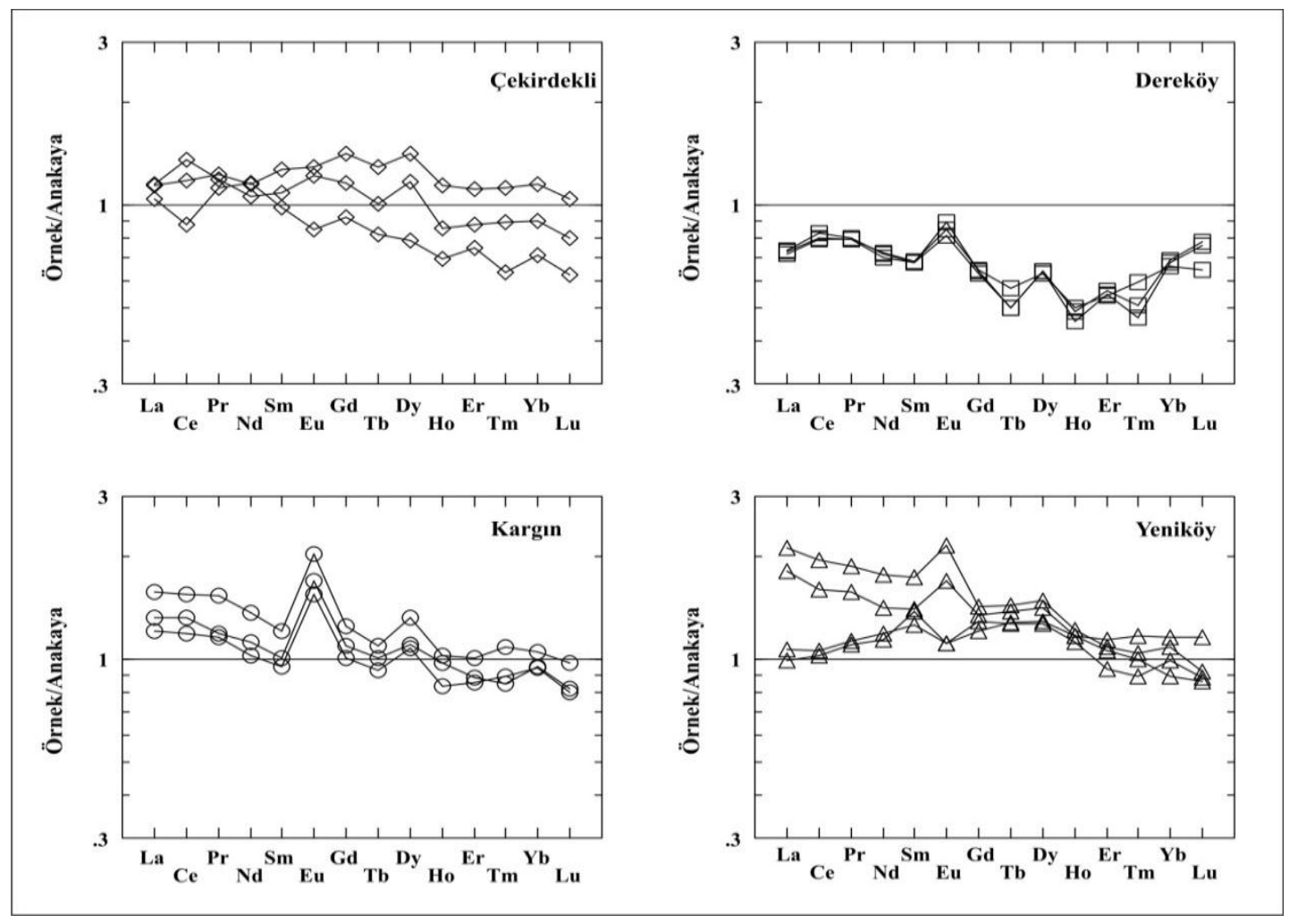

Şekil 7. Bentonite dönüşüm sırasında nadir toprak elementlerinin değişim diyagramı

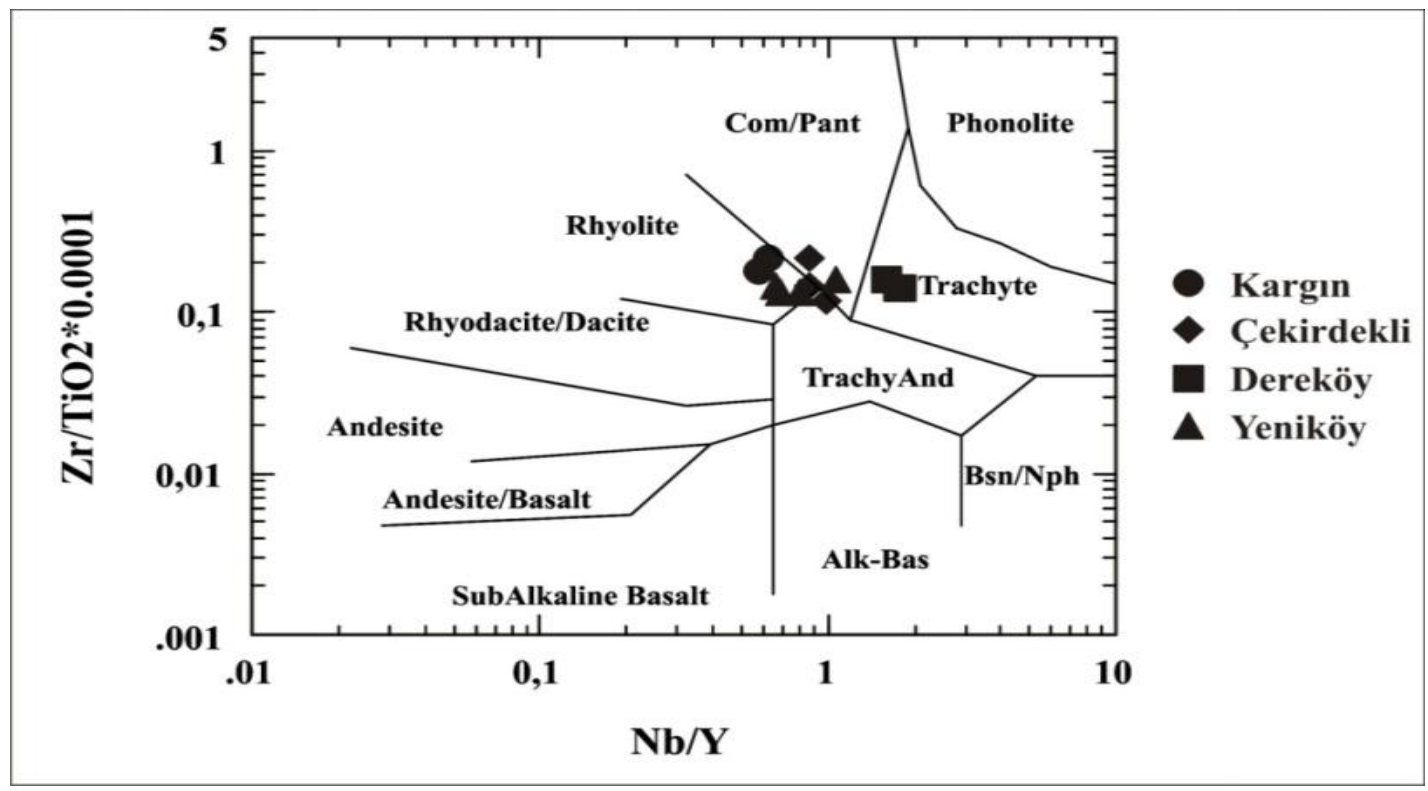

Şekil 8. Bentonitlerin $\mathrm{Zr} / \mathrm{TiO}_{2}-\mathrm{Nb} / \mathrm{Y}$ diyagramındaki yeri [23] 
10 ile 30 metre arasında değişen kalınlık gösterir ve kireçtaşları ile örtülüdür. XRD incelemelerine göre dioktaedral smektit (montmorillonit) bentonitlerin esas mineralidir. Feldspat (plajiyoklas, sanidin), silis mineralleri (opal-CT, kristobalit, kuvars), biyotit, düşük Mg'lu kalsit, Ca-dolomit, kaolinit, illit, alünit ve zeolit (klinoptilolit) değişik oranlarda bileşime katılan diğer minerallerdir. Asitik karakterli volkanikler ve andezitik tüflerin bentonite dönüşümünde element hareketliliği gerçekleşir. Bentonitte zenginleşen $\mathrm{Al}_{2} \mathrm{O}_{3}, \mathrm{TiO}_{2}$, Th, Ta, Hf, Sb yerinde zenginleşme yoluyla; $\mathrm{MgO}, \mathrm{CaO}, \mathrm{Sc}, \mathrm{Sr}, \mathrm{P}, \mathrm{Cr}, \mathrm{Co}$ zenginleşmesi ise yapısal birleşme, iyon değişimi veya ikincil sulu Fe-Mn oksitlerin adsorbsiyonuyla olur. Element kaybı ise açık sistem nedeniyle element göçü ve çözünebilen iyonlar veya komplekslerin taşınması ile gerçekleşir. $\mathrm{SiO}_{2}$, $\mathrm{Na}_{2} \mathrm{O}, \mathrm{K}_{2} \mathrm{O}, \mathrm{Cs}, \mathrm{Rb}, \mathrm{U}$ ve $\mathrm{Zr}$ alterasyonun ilk evrelerinde kayba uğrayarak ilerleyen alterasyona bağlı olarak sistemden taşınır ve bentonit bu elementlerce fakirleşir [15,16,18,22,24,25].

Bentonitlerin kimyasal analiz sonuçları, ana kayaca göre normalize edilmiş değişim diyagramları ve $\mathrm{Al}_{2} \mathrm{O}_{3}-\mathrm{MgO} / \mathrm{CaO} / \mathrm{Fe}_{2} \mathrm{O}_{3}$ ikili diyagramları; 4,44 ile 8,25 kat $\mathrm{MgO}$ ve 1,70 ile 3,22 kat $\mathrm{CaO}$ zenginleşmesinin, dış kaynaklı olduğuna işaret etmektedir. İncelenen bentonitlerde zenginleşen Mg'un bir kısmı montmorillonit yapısında tutulmuş, geriye kalan $\mathrm{Mg}$ ise dolomit oluşumunda kullanılmış olmalıdır. Bentonitlerdeki dolomit mineralleri bunu desteklemektedir. Bentonitlerin içinde magnezyumca yüksek fazların bulunmaması, Yeniköy ve Dereköy bentonitlerinin bulunduğu bölgede ofiyolitlerin ve KD-GB yönlü fayların; Çekirdekli ve Kargın bölgelerinde yine D-B ve KB-GD yönlü fayların bulunması [1-3], Mg'un bu faylara bağlı olarak yöredeki ofiyolitik kayaçlardan hidrotermal getirimler yoluyla sağlanmış olabileceğini düşündürmektedir. Bentonitlerdeki (kuvars+kaolinit) \pm alünit mineral parajenezi, Çekirdekli bölgesinde hidrotermal aktivite sonucu gelişen gözenekli (vuggy) kuvars mineralizasyonu [9], bentonitler üzerinde yapılan duraylı izotop $\left(\delta^{2} \mathrm{H}, \quad \delta^{18} \mathrm{O}\right)$ çalışmaları [26] bölgedeki hidrotermal aktivite varlığını desteklemektedir. Montmorillonitte Ca'un yüksek miktarda değişebilir katyon olarak bulunması [4], $\mathrm{CaO}$ zenginleşmesinin iyon değişimi yoluyla gerçekleştiğine işaret eder [27,28]. Zenginleşen Ca’un bir kısmı değişebilir katyon olarak montmorillonit yapısında tutulmuş geriye kalan $\mathrm{Ca}$, bentonitler içinde gözlenen kalsit oluşumunda kullanılmıştır.

Volkanik camın su alarak çözünmesi sırasında; Na çözünerek göçeder ve difüzyon yolu ile Si tüketilir [28-30] ve alterasyon ürünü malzeme (bentonit) $\mathrm{Si}$ ve $\mathrm{Na}$ yönünden fakirleşir. İncelenen bentonitlerde $\mathrm{Na}, \mathrm{K}$ ve $\mathrm{Si}$ alterasyon ile birlikte çözünerek tüketilmiş, çözünen silisin bir kısmı smektit oluşumunda kullanılmış geriye kalan fazla $\mathrm{Si}$, bentonitlerdeki silis minerallerinin (kristobalit, opal-CT ve kuvars) oluşumunu sağlamıştır [31]. Benzer olarak ana kayadan çözünen $\mathrm{Na}$ ve K'da dioktaedral smektitlerde değişebilir katyon olarak kullanılmış, K'un bir kısmı ise illit oluşumunda kullanılmış olmalıdır. Bentonitleşme sırasında ana kayalardan çözünen $\mathrm{Cs}$ ve $\mathrm{Rb}$; alkaliler $(\mathrm{Na}, \mathrm{K})$ ile birlikte hareket ederek hızla mobilize olmuş ve ilerleyen alterasyona bağlı olarak sistemden taşınmıştır. Sr ise dioktaedral smektitlerde iyon değişimi ile tabakalararası değişebilir katyon olarak tutularak zenginleşmiştir. Tüm bentonitlerdeki Zn zenginleşmesi dış kaynaklı bir zenginleşmeye; $\mathrm{U}$ kayıpları ise bentonitleşme sırasında indirgen bir ortama işaret eder.

Volkanik cam, dasitik-andezitik tüf gibi volkanik kayaçların bentonite alterasyonu ile nadir toprak elementleri (REE)'nin bentonitte zenginleşmesi, yerinde ve yer değiştirme yoluyla olur. Alterasyon sırasında erimeyen REE bileşenlerini tutan manyetit, zirkon, allanit vb. aksesuar mineraller ve (baz1) hidrotermal sistemlerdeki $\mathrm{F}, \mathrm{Cl}, \mathrm{SO}_{4}$ gibi elemanlar bentonitte özellikle LREE'nin yerinde zenginleşmesini sağlar [16,18,20,21]. Neoforme fillosilikat ve otijenik fosfat minerallerinin varlığ ise bentonitteki REE içeriklerinin azalmasını sağlar [18,22,24,32]. İnceleme bölgesindeki bentonitleşme sırasında ana kayalardan çözünen nadir toprak elementleri mobilize olmuş, ilerleyen alterasyona bağlı olarak hafif nadir toprak elementleri (LREE)'nde bir zenginleşme, ağır nadir toprak elementleri (HREE)'nde ise kayıp gerçekleşmiştir. Dereköy bentonitinde maksimum 
REE kaybı meydana gelmiştir. Yeniköy ve Kargın bentonitlerindeki alünit, ilgili bentonitlerdeki LREE zenginleşmesine neden olmuş olmalıdır. Özellikle Dereköy ve Çekirdekli bentonitlerinde saptanan illit'in, ilgili bentonitlerdeki HREE'nin azalmasına neden olduğu düşünülmektedir. Eu'un tüm bentonitlerde değişik zenginleşme göstermesi sıcaklığın yüksek olabileceğine işaret etmektedir. Yeniköy bentoniti alt ve üst seviyelerindeki $\mathrm{Eu}$ zenginleşme farklılıkları ise bu bölgede özellikle ortam değişikliğini net olarak yansıtmaktadır. Diğer taraftan gerek köken kaya diyagramındaki ve gerekse ana kayaya göre normalize edilmiş REE desenlerindeki farklılıklar bentonitlerin değişik bileşimli kayalardan türediklerini ifade eder. Bigadiç bölgesi bentonit yatakları üzerinde yapılan mineralojik-jeokimyasal incelemeler, değişik bileşimli tüflerin bentonite alterasyonu ile element hareketliliği gerçekleştiğini ve alterasyona bağlı olarak $\mathrm{SiO}_{2}, \mathrm{Na}_{2} \mathrm{O}, \mathrm{K}_{2} \mathrm{O}, \mathrm{Cs}, \mathrm{Rb}, \mathrm{U}, \mathrm{Y}$ kayıpları, $\mathrm{Al}_{2} \mathrm{O}_{3}, \mathrm{Fe}_{2} \mathrm{O}_{3}, \mathrm{MgO}, \mathrm{TiO}_{2}, \mathrm{Zr}, \mathrm{Sr}$ ve $\mathrm{Zn}$ zenginleşmeleri meydana geldiğini gösterir. Alterasyon ortamındaki değişiklikler (kısmen sıcaklık yükselmesi, hidrotermal katkı, indirgen ortam) ve farklı bileşimdeki ana kaya nadir toprak elementlerinin değişik davranmasına neden olmuştur.

\section{TEŞEKKÜR}

Yazar, arazi çalışmalarına katılan Dr. G. Büyükkahraman ve O. Özbay'a; çizimleri yapan C. Bircan ve İ. Altın'a teşekkür eder.

\section{KAYNAKLAR}

1. Çoban, F., Kocabaş, C., 2007. Bigadiç Bentonit Yatakları: Mineralojisi, Jeokimyası ve Kökensel Yorumu. Balıkesir Üniversitesi Bilimsel Araştırma Projeleri Birimi, Proje No: BAP 2006/32, Balıkesir, 66 sf.,

2. Çoban, F., Büyükkahraman, G., 2010. Balıkesir Bölgesi Bentonit Oluşumlarının Mineralojik Jeokimyasal Özellikleri; Bentonitleşme Sirasındaki Element Mobilizasyonları. 35. Y1l Jeoloji Sempozyumu, Poster Bildiri, Konya.

3. Kocabaş, C., Çoban, F., 2005. The Mineralogy and Geochemistry of a Bentonite Deposit
Between Yeniköy and Akçakertil (Bigadiç). Intern. Earth Sciences Colloq. on the Eagean Regions, IESCA 2005. Proocedings: 213-220.

4. Kocabaş, C., Çoban, F., 2007. Bigadiç (Balıkesir) Yöresinde Camsı Tüf-Bentonit Dönüşümünü Sağlayan Alterasyonun Mineralojisi ve Elementsel Hareketliliği. XIII. Ulusal Kil Sempozyumu, sf: 65-79, Isparta.

5. Brindley, G. W., Brown, G., 1980. Crystal Structures of Clay Minerals and their Identification in Brindley, G. W., Brown, G., Eds, X-Ray Diffraction Procedures for Clay Mineral Identification, 305-360, Mineralogical Society, London.

6. Pickering, K.T., Marsh, N.G., Dickie, B., 1993. Data report: in Organic Major, Trace and Rare Earth Element Analyses of the Muds and Mudstones from Site 808, in Hill, I. A, Taira, A., Firth, J. V., et al., Proc. Ocean Drilling Program, Scientific Results, 131, 427-432.

7. Erkül, F., Helvac1, C., Sözbilir, H., 2005 b. Stratigraphy and Geochronology of the Early Miocene Volcanic Units in the Bigadiç Borate Basin, Western Turkey. Turkish Journal of Earth Sciences, 14 (3), 227-253.

8. Helvac1, C., 1995. Stratigraphy, Mineralogy and Genesis of the Bigadiç Borate Deposits, Western Turkey. Economic Geology, 90, 1237-1260.

9. Erkül, F., Helvacı, C., Sözbilir, H., 2006. Olivine Basalt and Trachyandesite Peperites Formed at the Subsurface/Surface Interface of a Semi-Arid Lake: An Example from the Early Miocene Bigadiç Basin, Western Turkey. Journal of Volcanology and Geothermal Research, 149 (3-4), 240-262.

10.Moore, D. M., Reynolds, Jr. R. C., 1997. X-Ray Diffraction and the Identification and Analysis of Clay Minerals. Oxford University Press, New York, 378pp.

11.Wilson, M. J., 1987. A Handbook of Determinative Methods in Clay Mineralogy. Blackie and Son, London, 384.

12. Williams, L.A., Parks, G.A., Crerar, D.A., 1985. Silica Diagenesis, I. Solubility Controls. Journal Sedimentary Petrology, 55, 301-311.

13. Goldsmith, J.R., Graf, D.L.,1958. Structural and Compositional Variations in some Natural Dolomites. Journal Geology,66, 678-692. 
14. Hardy, R., Tucker, M., 1988. X-ray Powder Diffraction on Sediments: in Tucker, M., Ed, Techniques in Elements. Chemical Geology, 20, 325-343, 1977. Sedimentology, Blackwell Scientific Publ, 364,

15. White, A.F., 1983. Surface Chemistry and Dissolution Kinetics of Glassy Rocks at $25^{\circ} \mathrm{C}$. Geochimica Cosmochimica Acta, 47, 805-815.

16. Zielinski, R.A., 1982. The Mobility of Uranium and other Elements During Alteration of Rhyolite Ash to Montmorillonite: A Case Study in the Troublesome Formation, Colorado, U.S.A. Chemical Geology, 35, 185-204.

17. Zielinski, R.A., 1979. Uranium Mobility During Interaction of Rhyolitic Obsidian, Perlite and Felsite with Alkaline Carbonate Solution: $\mathrm{T}=120^{\circ} \mathrm{C}, \mathrm{P}=210 \mathrm{~kg} / \mathrm{cm}^{2}$, Chemical Geology, 27, 47-63.

18. Christidis, G., 1998. Comperative Study of the Mobility of Major and Trace Elements During Alteration of an Andesite and a Rhyolite to Bentonite, in the Islands of Milos and Kimolos Aegean, Greece. Clays and Clay Minerals, 46(4), 379-399.

19. Lipin, B.R., McKay, G.A., 1989. Geochemistry and Mineralogy of Rare Earth Elements, the Mineralogical Society of America, Washington, D.C., 278pp.

20. Wood, S. A., 1990a. The Aqueous Geochemistry of Rare Earth Elemets and Ytrium, 1. Review of Avaliable LowTemperature Data for Inorganic Complexes and the Inorganic REE Speciation of Natural Waters. Chemical Geology, 82, 159-186.

21. Wood, S. A., 1990b. The Aqueous Geochemistry of the None-Earths and Ytrium, 2. Theoretical Predictions of Speciation Hydrothermal Solution Water Pressure at $350^{\circ} \mathrm{C}$. Chemical Solution of Geology, 88, 99-125.

22. Christidis, G. E., Scott, P. W., Marcopoulos, T., 1995. Origin of the Bentonite Deposits of Eastern Milos, Aegean, Greece. Geological, Mineralogical and Geochemical Evidence. Clays and Clay Minerals, 43, 63-67.

23. Winchester, J. A., Floyd, D. A., 1977. Gechemical Discrimination of Different
Magma Series and their Differantiation Products Using Immobile Elements, Chemical Geology 20, 325-343.

24. Christidis, G., Scott, P.W., 1997. The Origin and Control of Colour of White Bentonites from Aegean Islands of Milos and Kimolos, Greece. Mineralium Deposita, 32, 271-279.

25. Shiraki, R., Sakai, H., Endoh, M., Kishia, N., 1987. Experimental Studies on Rhyolite and Andesite Seawater Interactions at $300^{\circ} \mathrm{C}$ and 1000 bars. Geochemical Journal, 21, 139148.

26. Çoban, F., Büyükkahraman, G., Özbay, O., Yılmaz, E., 2013. Sinandede, Danaçayır (Sındırgı, Balıkesir) Kaolin Oluşumları ile Bigadiç (Balıkesir) Bölgesi Bentonitlerinin $\delta^{18} \mathrm{O}, \delta^{2} \mathrm{H}$ ve $\delta^{13} \mathrm{C}$ İzotopları Yardımıla Kökensel Karşılaştırılması. 15. Ulusal Kil Sempozyumu (Poster bildiri), Niğde.

27. Shiraki, R., Iiyama, T., 1990. Na-K Ion Exchange Reaction Between Rhyolitic Glass and $(\mathrm{Na}, \mathrm{K}) \mathrm{Cl}$ Aqueous Solution Under Hydrothermal Conditions. Geochimica Cosmochimica Acta, 54, 2923-2931.

28. White, A.F., Claasen, H.C., 1980. Kinetic Model Forthe Short-Term Dissolution of a Rhyolitic Glass. Chemical Geology, 28, 91109.

29. Aramaki, S., Lipman, P.W., 1965. Possible Leaching of $\mathrm{Na}_{2} \mathrm{O}$ During of Volcanic Glasses. Proceedings of the Japan Academy, 41, 467-470.

30. Noble, D.C., 1967. Sodium, Potassium and Ferrous Iron Contents of Some Secondary Hydrated Natural Silicic Glasses. American Mineralogist, 52, 280-286.

31. Gündoğdu, M. N., Yalçın, H.., Temel, A., Claner, N., 1996. Geological, Mineralogical and Geochemical Charecteristics of Zeolite Deposits Associates with Borates in the Bigadiç, Emet and Kırka Neogene Lacustrine Basins, Western Turkey. Mineralium Deposita, 31 (6), 492-513.

32. Starke, R., 1991. Trace Element of Clay Minerals. Proceedings of the $7^{\text {th }}$ Euroclay Conference, Dresden, 989-994. 